\title{
Persistent akathisia associated with early tardive dyskinesia
}

\author{
THOMAS R. E. BARNES \\ M.B., B.S., M.R.C.Psych. \\ WALTER M. BRAUDE \\ M.B., Ch.B., D.P.M., M.R.C.Psych.
}

\begin{abstract}
Psychiatric Research Unit, University of Cambridge Clinical School, Addenbrooke's Hospital, Trumpington Street, Cambridge CB2 $2 Q E$
\end{abstract}

\begin{abstract}
Summary
Two psychiatric patients developed moderate or severe oro-facial dyskinesia, and limb dyskinesia, at a relatively young age and within a year of starting antipsychotic drug-treatment. This early appearance of tardive dyskinesia was preceded by akathisia that had developed at the beginning of drug therapy and persisted, despite the reduction of their drug doses to maintenance levels. The possibility that persistent akathisia may herald the early onset of tardive dyskinesia, is discussed.
\end{abstract}

KEY WORDS: schizophrenia, parkinsonism.

\section{Introduction}

Tardive dyskinesia is a movement disorder associated with the administration of antipsychotic (dopamine antagonist) drugs and, as its name suggests, has been considered as a side-effect of late-onset. It is characterized by oro-facial and limb dyskinesia. Akathisia is a syndrome of motor restlessness also related to antipsychotic medication and usually described as an acute, dose-related phenomenon. In our recent study (Braude, Barnes and Gore, 1983) of akathisia developing during the in-patient treatment of acute psychiatric patients, the condition was invariably ameliorated by a reduction in drug dose. This finding is in accord with the clinical literature on akathisia which suggests that dosage reduction is the only consistently effective treatment strategy (Hodge, 1959; Raskin, 1972; Van Putten, 1974). In the two patients described here, akathisia persisted despite a reduction in the dose of their antipsychotic medication, from high doses of oral drugs during hospital admission to maintenance doses of depot preparations. This persistent akathisia heralded the early appearance of tardive dyskinesia.

\section{Case 1}

A 32-year-old unemployed single woman was admitted to hospital in July 1981 and diagnosed as suffering from a schizophrenic illness. This was the first occasion that she had been prescribed antipsychotic medication, although there was evidence that psychotic symptoms, principally delusions, had been present for several years. She was treated initially with oral chlorpromazine to a maximum dose of 500 $\mathrm{mg}$ per day. Following a test dose of fluphenazine decanoate (Modecate), $12.5 \mathrm{mg}$ i.m., she was started on regular injections of this depot drug, $37.5 \mathrm{mg}$ i.m. every 3 weeks. Within a few days of the first injection she complained of an inability to keep her legs still and the need to pace up and down persistently. Her feelings of restlessness were most distressing when standing, when she would rock from foot to foot, or walk around, to gain respite. Myoclonic jerking of the feet was also observed. These signs and symptoms are characteristic of severe akathisia according to diagnostic criteria derived from our recent study (Braude et al., 1983). However, only minimal signs of parkinsonism were present; rating 0.4 on the Simpson and Angus (1970) Extrapyramidal Rating Scale (EPRS). There was no evidence of tardive dyskinesia. She was treated with procyclidine, $5 \mathrm{mg}$ tds, for 4 weeks without benefit.

She was discharged to outpatient care in November 1981. Despite a further course of treatment with procyclidine, $5 \mathrm{mg}$ bd, her akathisia persisted unchanged. The condition remained severe and distressing, and proved to be a profound social handicap as she was unable to tolerate standing still for even the shortest periods of time. By February 1982 she had developed moderate oro-facial dyskinesia, according to the videotape rating technique for tardive dyskinesia described by Barnes and Trauer (1982). Six months later the oro-facial dyskinesia was rated as severe, and choreiform movements of all four limbs were present. Since discharge from hospital, her antipsychotic medication had remained unchanged, fluphenazine decanoate $37.5 \mathrm{mg}$ i.m. every 3 weeks. 
Case 2

A 37-year-old male welder was admitted for the first time in February 1981 with a full range of Schneiderian first-rank symptoms of schizophrenia. He was diagnosed as having paranoid schizophrenia and prescribed chlorpromazine to a maximum of 500 $\mathrm{mg}$ per day and trifluoperazine to a maximum of 30 mg per day. This was the first occasion that he had received antipsychotic medication. Within 10 days of starting drug treatment he developed moderately severe akathisia, manifesting fidgety leg movements while seated, rocking from foot to foot when standing and complaining of being unable to keep his legs still. Parkinsonism was also moderately severe, scoring 1.4 on the EPRS. There was no evidence of tardive dyskinesia at this time. Procyclidine was prescribed, up to $15 \mathrm{mg}$ per day, which partially ameliorated his parkinsonism to a score of $0 \cdot 8$, but his akathisia was unaffected. The chlorpromazine and trifluoperazine were gradually withdrawn and replaced by fluphenazine decanoate $37.5 \mathrm{mg}$ i.m. three weekly. However, his akathisia persisted unaltered. Four months after admission he was noted to have mild oro-facial dyskinesia. Two months later his oro-facial dyskinesia was rated as moderate, and dystonic movements of the legs had appeared. Over the following 6 months his depot medication was gradually reduced, so that by February 1982 he was receiving fluphenazine decanoate $25 \mathrm{mg}$ every four weeks. The signs and symptoms of akathisia and the severity of his oro-facial and limb dyskinesia remained unchanged.

\section{Discussion}

By virtue of their age, the two patients described above might be considered to be at a low risk of developing tardive dyskinesia (Jus et al., 1976; Smith and Baldessarini, 1980; Kane and Smith, 1982). However, within a year of starting antipsychotic drug therapy they had developed marked oro-facial dyskinesia and prominent limb dyskinesia. These abnormal movements were considered to represent tardive dyskinesia, although stereotyped, rhythmic movements occurring relatively early in drug treatment, and resembling tardive dyskinesia, have been observed by Gerlach (1979), and could be a source of diagnostic confusion. He labelled these phenomena 'initial hyperkinesia'. However, there is little evidence, at present, to support the claims that this hyperkinesia constitutes a phenomenologically distinct clinical entity, or may be distinguished from tardive dyskinesia in terms of response to drug treatments. Tardive dyskinesia itself lacks precise phenomenological description and, as generally applied, the term may encompass a wide variety of abnormal movements (Mackay, 1982; Barnes, Rosser and Trauer, 1983b). In the two patients described here, oro-facial dyskinesia, which represents the cor sign of any definition of tardive dyskinesia, waQ assessed using a rating method with establishe reliability and validity (Barnes and Trauer, 1982R Coexistent limb dyskinesia was choreiform in nature. in one case, and dystonic in the other.

For both patients, their psychiatric histories and the presentation of their schizophrenic illness were not unusual, and the drug treatment administere 5 . was representative of current practice. Neither had $F$ family history of movement disorders, and on admise sion there had been no clinical evidence of neurologien cal pathology, or systemic illness. Thus, the clinicat features and management of these cases were not atypical. The only remarkable factor, common to both cases, was the presence of akathisia which hag persisted despite drug dose reduction. Evidence frot a number of clinical studies shows that akathisia an tardive dyskinesia can co-exist (Brandon, McClef land and Protheroe, 1971; Kennedy, Hershon and McGuire, 1971; Wojcik et al., 1980; Mukherjee et al w 1982; Barnes, Kidger and Gore, 1983). Such ac⿷ association may appear paradoxical, as akathisia if an acute, dose-related condition which tends to occur at the start of antipsychotic drug therapy and is readily reversible with a reduction in drug dosage while tardive dyskinesia usually emerges during stable, maintenance medication or on drug witheo drawal, and is more common in older patients.

The cases reported here suggest one possitio explanation for the association of these two contio tions, namely that acute akathisia which persists wit maintenance antipsychotic medication may be specific antecedent of early tardive dyskinesia. Thero are isolated clinical reports in the literature that len 8 support to this view. Based on their clinical observaê tions, Chouinard et al. (1979) considered that $\vec{a}$ patient with tremor or akathisia, which they de scribed as 'hyperkinetic' symptoms of parkinsonism. was more likely to manifest tardive dyskinesia than patient with 'hypokinetic symptoms' such as akinesia. and rigidity. DeVeaugh-Geiss (1982) elaborated on this idea, suggesting that, in certain patients, akathi sia can represent a stage in a progression from? hypokinetic parkinsonism to the development of orofacial and trunk and limb dyskinesia. Munetz an\& Cornes (1982) discussed this hypothesis, and specul lated further on the relationship between the two. conditions. They suggested that tardive dyskinesids may be preceded by a form of akathisia where only the motor signs are present; the subjective, distressin 8 aspects originally in evidence, having progressively diminished. Simpson (1977) has also commented of the absence of subjective symptoms in chronico akathisia, and, in addition, has noted the existence of a late-onset type of akathisia which he considered to be 'frequently associated' with tardive dyskinesia 
Braude and Barnes (1983) have proposed that lateonset akathisia, emerging during chronic antipsychotic drug treatment, might indicate the development of 'covert' dyskinesia, trunk and limb dyskinesia being manifest on subsequent drug dose reduction. Inherent in all these reports is the notion that akathisia may be a forerunner of tardive dyskinesia when it occurs in a context other than the commonly observed association with a relatively short period of elevated drug dose.

\section{References}

Barnes, T.R.E., Kidger, T. \& Gore, S.M. (1983a) Tardive dyskinesia: a 3-year follow-up study. Psychological Medicine, 13, 71

Barnes, T.R.E., Rossor, M. \& TRauer, T. (1983b) A comparison of purposeless movement in psychiatric patients treated with antipsychotic drugs, and normal individuals. Journal of Neurology, Neurosurgery and Psychiatry, 46, 540.

BARNES, T.R.E. \& TRAUER, T. (1982) Reliability and validity of a tardive dyskinesia videotape rating technique. British Journal of Psychiatry, 140, 508.

Brandon, S., MCClelland, H.A. \& Protheroe, C. (1971) A study of facial dyskinesia in a mental hospital population. British Journal of Psychiatry, 118, 171.

BRAUDE, W.M. \& BARNES, T.R.E. (1983) Late-onset akathisia: an indicant of covert dyskinesia. Two Case Reports. American Journal of Psychiatry, 140, 611.

BRAUDE, W.M., BARNES, T.R.E. \& Gore, S.M. (1983) Clinical characteristics of akathisia: a systematic investigation of acute psychiatric inpatient admissions. British Journal of Psychiatry, 143, 139.

Chouinard, G., Annable, L., Ross-Chouinard, A. \& Nestoros, J.N. (1979) Factors related to tardive dyskinesia. American Journal of Psychiatry, 136, 79.

Deveaugh-Geiss, J. (1982) Prediction and prevention of tardive dyskinesia. In: Tardive Dyskinesia and Related Involuntary Move- ment Disorders (Ed. J. DeVeaugh-Geiss), p. 161. John Wright, PSG Inc, Boston.

GerLaCh, J. (1979) Tardive dyskinesia. Danish Medical Bulletin, 26, 209.

HODGE, J.R. (1959) Akathisia: the syndrome of motor restlessness. American Journal of Psychiatry, 116, 337.

Jus, A., Pineau, R., Lachance, R., Pelchat, G., Jus, K., Pires, P. \& Villeneuve, R. (1976) Epidemiology of tardive dyskinesia. Part. I. Diseases of the Nervous System, 37, 210.

KANE, J.M. \& SMITH, J.M. (1982) Tardive dyskinesia: prevalence and risk factors 1959-1979. Archives of General Psychiatry, 39, 473.

KenNedy, P.F., Hershon, H.I. \& MCGUIRE, R.J. (1971) Extrapyramidal disorders after prolonged phenothiazine therapy. British Journal of Psychiatry, 118, 509.

MACKAY, A.V.P. (1982) Clinical controversies in tardive dyskinesia. In: Neurology 2, Movement Disorders (Eds. C. D. Marsden \& S. Fahn), p. 248. Butterworth Scientific, London.

Mukherjee, S., Rosen, A.M., Cardenas, C., Varia, V. \& Olarte, S. (1982) Tardive dyskinesia in psychiatric outpatients. Archives of General Psychiatry, 39, 466.

MUNETZ, M.R. \& CORNES, C.L. (1982) Akathisia, pseudoakathisia and tardive dyskinesia: clinical examples. Comprehensive Psychiatry, 23, 345 .

RASKIN, D.E. (1972) Akathisia: a side-effect to be remembered. American Journal of Psychiatry, 129, 345.

SIMPSON, G.M. (1977) Neurotoxicology of major tranquilizers. In: Neurotoxicology, Vol. l (Eds. L. Roizin, H. Shiraki \& N. Grčević), p. I. Raven Press, New York.

SIMPSON, G.M. \& ANGUS, J.W.S. (1970) A rating scale for extrapyramidal side-effects. Acta Psychiatrica Scandinavica, 212 (Suppl. 44), 11.

SMITH, J.M. \& Baldessarini, R.J. (1980) Changes in prevalence, severity and recovery in tardive dyskinesia with age. Archives of General Psychiatry, 37, 1368.

VAN PutTEN, T. (1974) Why do schizophrenic patients refuse to take their drugs? Archives of General Psychiatry, 31, 67.

WoJCIK, J.D., GelenberG, A.J., LA BRIE, R.A. \& MiesKe, M. (1980) Prevalence of tardive dyskinesia in an outpatient population. Comprehensive Psychiatry, 21, 370.

(Accepted 18 April 1983) 